\title{
Chapter 18 \\ Toward an Equitable Distribution of Urban Green Spaces for People and Landscapes: An Opportunity for Portland's Green Grid
}

\author{
Vivek Shandas and Dana Hellman
}

\begin{abstract}
Portland, Oregon, has a relatively long history of progressive planning, environmental protection, and implementation of green infrastructure (GI) projects, enjoying associated benefits such as temperature reduction, energy savings, and aesthetic improvements. These efforts, while resulting in a robust suite of GI across the city, must be better coordinated to meet the challenges of the future. In this chapter, we provide an overview of GI implementation in Portland, emphasizing key projects and policies, as well as ongoing disparities in access to GI and its benefits. We then discuss the potential for activating a green grid in Portland by linking existing nodes of GI for maximum benefit. In addition to amplifying the positive biophysical effects of GI, we suggest that this approach can help alleviate ongoing socioeconomic disparities that make some communities more vulnerable to climate change and environmental degradation.
\end{abstract}

Keywords Green infrastructure - Socio-ecological resilience · Climate change · Environmental justice · Urban planning

\subsection{Introduction}

Green infrastructure (GI) is increasingly recognized as a crucial component of urban ecosystems, particularly as cities confront dual crises of climate change and degradation of environmental quality. In urban planning, discussions tend toward the immediate, biophysical or economic benefits of GI, including flood and heat control (Webber et al. 2020; Zölch et al. 2016), air quality improvements (Nowak et al. 2006), stormwater management (Copeland 2016; Eaton 2018), and carbon capture and climate change mitigation (Foster et al. 2011). This has been the case in Portland, Oregon, and in cities across the world (Meerow 2019; Naumann et al.

\footnotetext{
V. Shandas $(\bowtie) \cdot$ D. Hellman

Portland State University, Portland, OR, USA
} 
2011). However, recent scholarship suggests that GI can be more than a physical buffer between urban residents and looming environmental threats. It is a gateway through which urban planners and policymakers might respond to underlying disparities that create socio-ecological vulnerability and inhibit resilience (Bowen and Lynch 2017; Jennings et al. 2012; Zhu et al. 2019). If properly integrated, GI could be an essential tool enabling environmental justice and equity in the urban environment, alongside climate change mitigation, cost-effective risk reduction, and ecological protection.

Within the United States, Portland, Oregon offers a unique example of extensive municipal GI, which has been complemented by efforts in the private sector. Compared to other large cities on the US west coast and beyond, Portland features a relatively high density of urban canopy and other GI assets, as well as multiple GIsupportive programs and policies. Portland's progressive planning efforts have been well documented, including the establishment of an urban growth boundary in the 1970s and the earliest solid waste recycling program and the first climate action plan for a US city. Since the late1990s, Portland has been recognized for its pursuit of GI, decades before many other US cities. As such, it offers a compelling case through which to consider (1) the steps associated with successful GI implementation at a city scale and (2) opportunities to expand the positive effects of GI moving forward. Specifically, this chapter introduces the concept of a green grid.

The current state of GI in Portland is the result of a series of municipal efforts undertaken by various agencies. This work has largely been done ad hoc, implementing an uncoordinated array of GI features across the city. Such an approach was necessary in the early years of GI development, as municipal agencies experimented with different GI features, geographies, and linkages. While Portland now comprises a robust system of GI nodes (individual pieces of infrastructure), these are not well integrated. Completing the system by connecting existing nodes, and adding new ones where needed, is the next step toward effective, citywide GI. The green grid is a way of conceptually linking those disparate nodes to generate a protective grid of GI that encompasses the entire Portland area. While not yet a formal policy or project platform, this concept has been under consideration and development by cooperating agencies, including the Portland Bureau of Environmental Services, Bureau of Planning and Sustainability, Bureau of Transportation, and Department of Parks and Recreation.

In the subsequent sections, we will provide an overview of past GI projects and policies in Portland, illuminating the sociopolitical conditions that have allowed Portland to attain its current level of GI. We will then discuss divergent experiences of and access to GI and its effects on diverse human communities throughout the region. Finally, we will elaborate upon the need for a green grid model in planning and policymaking for the city of Portland. This includes conditions that must be in place to realize such an ideal and its potential to tackle a range of interrelated social and environmental issues through coordinated action. 


\subsection{An Abridged Overview of Green Infrastructure in Portland}

With over 13 million large trees, Portland's urban forest provides innumerable services to its residents and businesses, including improvements in air quality, temperature reduction during heat events, stormwater mitigation, and energy conservation. While tree canopy has received significant attention both from members of the public and local decision-makers, it is supplemented by a range of additional GI assets, including bioswales (features that capture and filter stormwater), water retention and detention ponds, ecoroofs (also called green roofs), and vegetated green streets (Figs. 18.1 and 18.2). These features did not emerge by chance but represent the culmination of decades of community effort and political will. In this section, we offer an overview of a few salient GI projects and policies that have emerged over the past three decades. These examples offer a glimpse into the sociopolitical conditions that advanced Portland's current suite of GI, which remains unrivaled in most cities in the world.

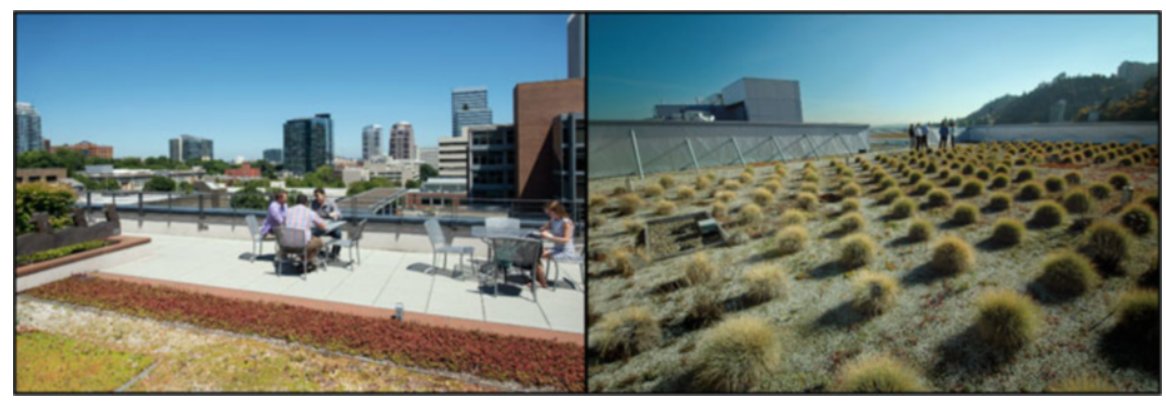

Fig. 18.1 Vegetated ecoroofs, also called green roofs. These features reduce stormwater runoff and pollution and provide wildlife habitat (Source: Portland State University)

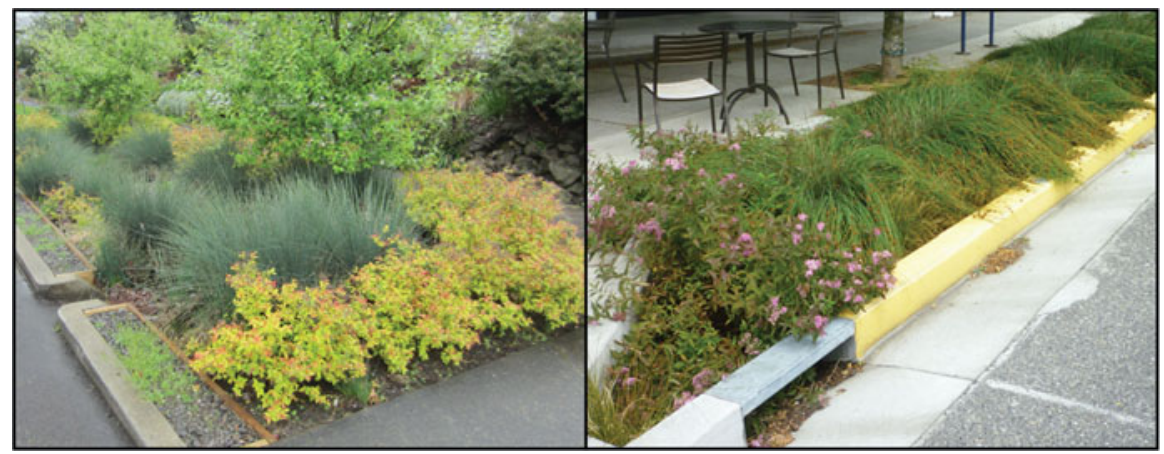

Fig. 18.2 Bioswales. These features capture stormwater and filter out pollutants (Source: City of Portland) 
One of the earliest attempts to advance green infrastructure in Portland began in the early 1990s. At this time, a legal case against the Bureau of Environmental Services resulted in a 20-year project to update municipal sewer and stormwater infrastructure. Central to this project, called Tabor to the River (T2R), was the creation of thousands of bioswales that would capture rainwater and reduce combined sewer overflows, the original reason for the 1990s lawsuit. The installation of these facilities resulted in extraordinary insights into the engineering, ecological and social dimensions of such an ambitious project. To date, several publications have highlighted the outcomes from the T2R project, and once finished, the City of Portland expanded the project to install similar GI assets across the region (Shandas and Messer 2008; BenDor et al. 2018). The US Environmental Protection Agency has since identified these facilities as exemplars of similar ones built in other parts of the country.

In 2015, the City implemented a Tree Code, which describes specific actions that must be taken when managing the urban forest. The Tree Code, which is known to city planners as Title 11, addresses questions about the role of the urban forester and trees in development situations and identifies and creates a series of staff positions that are responsible for different aspects of urban forest management. Emergent from the Tree Code was the creation of a Heritage Tree program, which offers a means for any community member to nominate a tree, based on social and ecological significance, as one that can stand in perpetuity. The Tree Code also outlines specific responsibilities from a community-based advisory group called the Urban Forestry Commission. Around this time, the City also passed an ordinance requiring ecoroofs in all new buildings in Downtown Portland and providing incentives for developers throughout the region to consider them as well. Finally, these changes coincided with a zoning approach that addressed "environmental overlay zones." This approach identifies specific areas in the city in which to apply zoning codes aimed at providing additional environmental protections during building or infrastructure development.

One of the most recent green infrastructure adoptions by the City of Portland is a green roof program, a component of the Central City 2035 Plan (City of Portland 2021). The EcoRoof Requirement, as it is called, began in 2018 and requires vegetated roofs covering $100 \%$ for new buildings or retrofits in the Central City over net 20,000 square feet. While this provision only applies to the Downtown area, it sets a precedent and has accelerated research on, applications of, and corporate interest in green roofs. The expectation is that this program will encourage households, businesses, the educational sector, and other facilities to implement their own green roofs, thereby diverting stormwater from the City's combined sewer and water system, while providing habitat for urban wildlife, including beneficial insects and birds.

Efforts to advance GI have been championed and implemented by numerous politicians, community groups, and municipal departments. These entities exhibit the potential to complement one another in pursuit of a shared goal of GI, though their work to date has often been uncoordinated. This approach has not been ineffective; Portland has been and continues to be a leader in GI, both within the 
United States and internationally. The culmination of 30 years of work provides a model for advancing GI elsewhere in the future. However, despite apparent progress, Portland is not without its environmental concerns. Green space is increasingly stressed by a growing urban population, the economic pressure for development, and conflicts over limited physical space. Additionally, tree loss has occurred across Portland owing both to climatic changes and pests that affect tree health. Even within the parameters of the protective Tree Code, developers are permitted to deviate from canopy cover requirements for a fee. The combined effects of human pressure and climate change pose a double threat to local communities and wildlife and a significant challenge for urban planners. Furthermore, impressive as Portland's current suite of GI may be, it is not evenly experienced by city residents. Rather, underlying socioeconomic inequities have meant that only segments of the population enjoy the benefits of GI, even as others are disproportionately exposed to environmental threats such as extreme heat, residential flooding, and air pollution.

\subsection{Outcomes and Experiences of Green Infrastructure in Portland}

The City of Portland has identified numerous, positive outcomes attributable to advancements in GI. These encompass physical and mental health, energy efficiency and decreased greenhouse gas emissions, aesthetic improvements, air quality improvements, and stormwater management (City of Portland 2010). Additional benefits have been well documented through case study research. For example, a study by Rao et al. (2014) found that Portland's current urban forest reduces annual healthcare costs by almost $\$$ five million by filtering nitrogen dioxide in the air, a byproduct of combustion that is a federally regulated pollutant. It has been further suggested that Portland's tree canopy can improve the birth outcomes of children (Donovan et al. 2011). Studies show that residential properties near green streets, large trees, and substantial canopy sell faster and for more money than similar homes without green features (Donovan and Butry 2011; Netusil et al. 2014); that communities living next to urban trees experience less isolation and fewer crimes, as well as greater engagement with neighbors and involvement with civic life (Shandas 2015); and that adding vegetation can decrease ambient temperatures in Portland's urban corridors and neighborhoods (Makido et al. 2019). These benefits are essential to social and economic well-being and can improve the quality of life for urban residents. However, local studies also reveal that communities across Portland do not share equally in these benefits. The map below shows the distribution of some notable GI elements, including tree canopy, ecoroofs, parks (open space), and bioswales, with notable differences in the concentration of these elements across the city (Fig. 18.3).

An examination of the distribution of Portland's urban forest indicates a sweeping range of canopy access, from $82 \%$ cover in some neighborhoods, to just $4 \%$ 

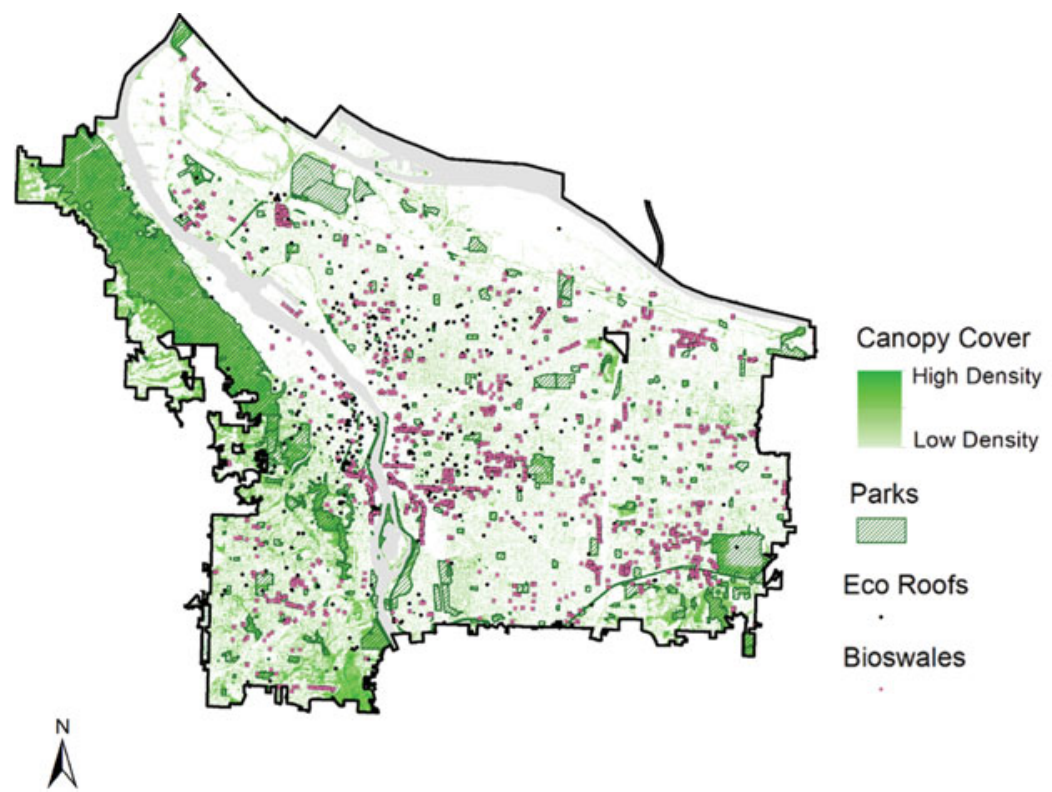

Parks

Eco Roofs

Bioswales

$0 \quad 1$ Miles

Fig. 18.3 Distribution of various GI elements in Portland, Oregon

in others (Fig. 18.4). While physical infrastructure and other urban features may preclude all areas of the city from having large tracts of forests, the current distribution suggests that some communities are disproportionately receiving benefits while others are not. A study by Voelkel et al. (2018) found that Portland's low-income residents and people of color (i.e., non-White), largely living on the city's east side, experienced higher summer temperatures than more affluent, White neighbors, largely concentrated on the west side. Additionally, Portland's history of redlining (that is, discrimination in housing sales based on race) can be understood as a facet of urban planning that has disproportionately situated people of color in highertemperature neighborhoods (Hoffman et al. 2020). Locally, observed differences in socioeconomic status and exposure to urban heat correspond with differences in access to tree canopy. In fact, the City of Portland has recognized these inequities and is in the process of developing strategies to expand canopy into historically underserved neighborhoods. The city defines low-canopy as less than $25 \%$ canopy coverage and low-income as $50 \%$ or more of an area (e.g., neighborhood), making less than $80 \%$ of the median household income. These definitions provide a means for identifying those areas that meet both criteria and developing outreach strategies to expand tree plantings.

Portland is bisected by the Willamette River, which runs south to north and comprises tributaries across the city. Low-lying neighborhoods, particularly on the east side of the river, are prone to residential flooding when moderate or heavy precipitation events occur. As with redlining and urban heat, past development prac- 


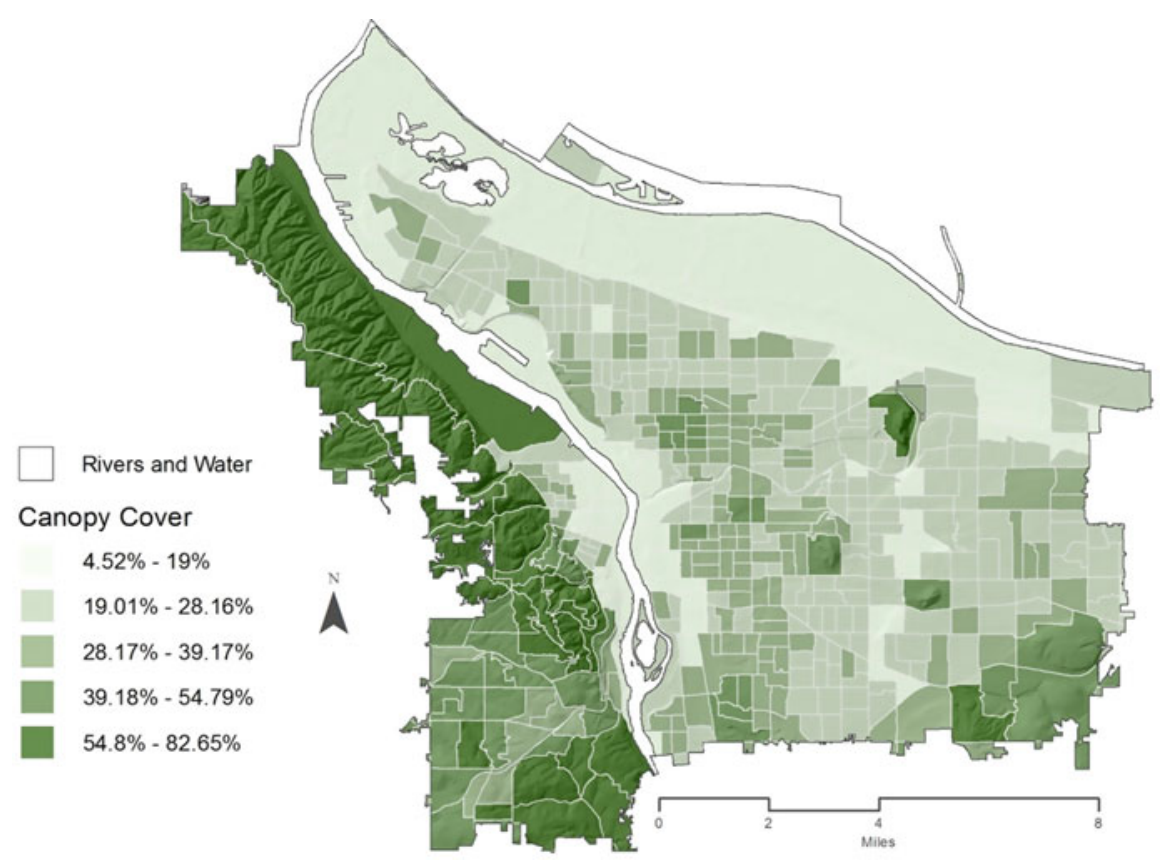

Fig. 18.4 Canopy cover in Portland, Oregon, visualized by census block group

tices have situated marginalized communities, especially those with low incomes, lower than average education, and people of color in floodplains, increasing their exposure to nuisance flooding (Kousky et al. 2020). A study by Fahy et al. (2019) found that flood exposure in Portland increased along spatial (east Portland) and socioeconomic lines. Unlike urban heat exposure and canopy access, Portland's GI assets related to urban flooding - specifically, green streets, bioswales, and ecoroofs-have already been concentrated in these high-risk, low-income areas (Chan and Hopkins 2017).

As planners and policymakers in Portland become more attuned to issues of equity and environmental justice, there is growing interest in targeting low-income or otherwise disinvested areas of the city with GI projects. The rationale is that all Portlanders should be able to enjoy green space and clean air and avoid flooding, extreme heat, and health assaults caused by poor environmental quality. However, this agenda is not without its complications. Sporadic GI investments may have the unintended consequence of making formerly disinvested neighborhoods more aesthetically pleasing, healthier or safer, raising property values and desirability (Ahmad et al. 2018). This in turn may lead to the displacement of area residents who were meant to be helped by GI upgrades, through a process sometimes referred to as "green gentrification" or "climate gentrification" (Anguelovski et al. 2019). This is a problem that may be exacerbated by the uncoordinated approach currently applied to GI planning in Portland. Unless all areas of Portland possess equitable access to 
GI, it is unlikely that those residents most exposed to environmental harm and most in need of GI's benefits will be able to enjoy them. Rather, piecemeal approaches to GI encourage displacement and perpetuate disparities between socio-ecological haves and have-nots.

Historical development patterns, planning policies, and structural bias in decision-making systems have created social inequities that permeate the built environment. Solutions to common problems of climate change and environmental degradation amplify or overlook vulnerability for some while providing relief and rewards to others. This has been true even in Portland, which has made great strides both in GI and urban sustainability, as well as equity-focused environmental planning. GI is not a panacea for poverty, racism, and the many wicked problems facing urban communities. Yet, coordinated, integrated applications of GI across the city offer an opportunity to expand access to the ecosystem benefits and environmental protection it affords.

\subsection{Next Steps: Activating the Green Grid}

Portland is well-covered by GI assets. Even portions of the city that have been historically disinvested contain an array of bioswales, parks, and ecoroofs. To advance a green grid within the city, we consider each of these assets as a spatially explicit node of GI activity with associated benefits. While all GI is managed by a patchwork of private and public entities, none act alone and are rather part of a mosaic of efforts to enable the myriad ecosystem services that emerge from each node, large or small. The informal network of GI managers includes homeowners, business owners, developers, and residents who often participate in volunteer activities to improve the urban ecosystem. While informal, these entities are critical to support and occasionally supplant official entities who often lack the capacity and resources and reach to actively steward the GI. In addition, the vast majority of GI is located on private lands, which precludes official public organizations such as the Bureau of Planning and Sustainability, the Bureau of Environmental Services, Portland Parks and Recreation, and Oregon Metro from actively stewarding these GI systems. Whether the activation of Portland's green grid is accomplished through informal networks or formal ones, it will require a level of coordination and accountability for ensuring the grid's long-term viability. In this section, we identify a few of the essential components in developing a coordination and accountability system that can help maintain and enhance Portland's green grid of GI.

While broad legislation and programs, including the tree code and ecoroof ordinance, apply uniform standards across the city, to date, the authors know of no known attempts to integrate GI across sites or maximize benefits through coordinated actions. Characterizing a set of GI nodes - similar to those in standard planning practices that identify urban development centers (see, for example, the City of Portland's 2035 Comprehensive Plan)_offers a means for more effectively integrating the spatial and institutional aspects of this work. Here, we argue for 
an activation of Portland's green grid by connecting those many biophysical and spatially explicit nodes of existing GI, developing an intentional, holistic, wellcoordinated strategy that aims to connect communities in need with beneficial GI and tackles environmental problems at the city scale. The green grid concept presents an opportunity to link up and integrate the many solitary components of Portland's GI landscape in response to the coordination and accountability challenges currently facing the region. We offer here a three-step approach for integrating the existing spatial nodes of GI and supporting a more coordinated effort that will ensure that urban ecosystems and communities will continue to receive essential ecosystem services from a green grid.

The first step is to describe the existing network of GI nodes across the city. This work has been underway by City officials but is not yet complete. While individual bureaus oversee specific aspects of each node-ecoroofs by Environmental Services, parks and trees by Parks and Recreation, etc.- developing a spatially explicit description of each of the green infrastructure features along with the entities that are responsible for their management can help to create an inventory for the current GI assets in the city. While definitions of GI vary from agency to community, we suggest maintaining a broad definition that encompasses the largest stretches of biophysical features that provide ecosystem services to areas of the city greater than a city block. Some attempts of such descriptions have emerged (Nascimento and Shandas 2021), though they are limited in terms of resolution and direct linkages to management entities. Of course, such descriptions will require highly granular data and the creation of a responsible entity that describes who might ensure the longevity of an individual node of GI. We have seen such efforts underway in several places around the world, including those mentioned in other parts of this GI compendium. We are not advocating for one entity to govern all the GI for an urban region but rather suggest an approach that identifies the specific GI nodes, functions, and expectations, which can translate into a co-management plan that ensures a coordinated response.

Second, we will need a means for understanding the distributional effects of GI in the city. As we mentioned earlier, the highly inequitable distribution of tree canopy provides communities with varying levels of ecosystem service, yet to date, we only have limited knowledge about the ways in which Portland's GI supports communities. Studies mentioned in the previous sections suggest potentially helpful ecosystem services associated with GI, though to date, the standards are largely based on its mere presence or absence. However, as we know from ecosystem studies, the health and overall quality of GI can vary depending on age, stress, maintenance, and other factors. More nuanced measures, variability, and qualitative outcomes associated with GI access and resulting ecosystem services are yet to be determined. A large tree, for example, provides greater amounts of ecosystem services to a community than a sapling. Assessing the quality of Portland's disparate GI is a herculean effort, requiring characterizations of the health and functioning of all features. Having recently completed the first exhaustive assessment of all public trees, which includes qualitative measurements of tree health, we know that the vast majority of green spaces are in private lands and will likely require a remotely 
sensed approach, such as Light Detection and Ranging (LiDAR) and hyperspectral assessments, to understand the health of GI. Efforts are currently underway to use remotely sensed data as a means for characterizing the quality of GI in Portland, though these will still require several years to complete. Coupling remotely sensed data with on-the-ground efforts to evaluate the ecosystem function of GI nodes will be an important second step to understanding the distributional effects of a green grid.

Coordination among formal and informal entities, taking inventory of GI, and characterizing the quality of ecosystem services can all be achieved through systematic and ongoing planning efforts. However, as a third step toward activating Portland's green grid, the City requires a collaborative approach that centers on values and ethics. This is essential for producing normative descriptions of GI and the contextual challenges facing it. Normative descriptions, in this case, will need to encompass a community conversation about preferable outcomes for Portland's green grid. What types of trees are preferable in which neighborhoods? How can we assign/adopt maintenance requirements? What forms of measurement will support an ecosystem function evaluation scheme? While calls for integrating community needs and perspectives into urban forestry efforts are gaining attention (Nascimento and Shandas 2021), still needed are approaches to articulate the extent to which diverse stakeholders view trees and GI as beneficial to community and individual health. If urban GI managers view its implementation simply as a matter of informing community members about the importance of trees, which has long been standard practice - such as one-way forms of communication-then opportunities to engage in broader discussions about equity will be lost. Arguably, much of the current emphasis on reconciling the disparate historical investments of GI within the Portland region has resulted in a prioritization of low-canopy and lowincome neighborhoods (City of Portland 2018). However, we argue that without an explicit focus on the immediate needs of community members, effectively advancing concepts such as the green grid will fail.

One potential approach for fulfilling the promise of Portland's green grid is the use of scenario analysis techniques (Caughman et al. 2020). Scenario analysis, as applied in this context, offers a means for evaluating the outcomes of a specific set of green grid options through engagement with a diverse mix of stakeholders. With facilitation about specific themes (e.g., neighborhoods GI assets, maintenance options, performance outcomes, etc.), scenario analysis allows for the necessary reflectivity and integration of multiple disciplinary perspectives for evaluating outcomes. In this context, scenarios and models can play an important role in enabling community members and decision-makers to consider the myriad aspects of risk and opportunity associated with a green grid. Scenario analysis, as such, may enlighten participants as to how the future is likely to unfold, illuminate potential risks, help them assess alternative pathways to address risks, and smooth all phases of project implementation. Scenarios are scalable, often used in global, regional, and national environmental assessments carried out over the last decade, for example, the Intergovernmental Panel on Climate Change's Assessment Reports, the Millennium Ecosystem Assessment; Convention on Biological Diversity's Global Biodiversity 
Outlook Reports, and United Nations Environment Programme's Environmental Outlook Reports. Nevertheless, we know of no uses of such an approach for advancing urban GI, which suggests a noteworthy oversight in the planning of our cities.

Integrating formal and informal organizational networks, describing and comprehensively documenting existing GI nodes, developing a functional basis for understanding and allocating ecosystems services, and developing normative approaches are fundamental pillars for achieving a robust green grid in Portland. If achieved, such a grid may offer protection against environmental threats while alleviating environmental disparities faced by Portland's most marginalized residents. A functional green grid means that the benefits of GI-clean air and water, cool temperatures, flood prevention, aesthetics — are enjoyed by all Portlanders, regardless of socioeconomic status or neighborhood of residence. Under the green grid, a robust system of GI assets covers the entire city, eliminating differences between those who do and do not have access. A green grid means that inequities associated with green gentrification may be avoided in the future because all parts of the city will be served. The implementation of GI in one neighborhood should not stimulate gentrification there if all neighborhoods are equally invested in. The coming decades will require even more care and intention to ensure that the existing charismatic mega-flora (i.e., old growth urban trees), along with the everyday shrubs and recently created bioswales, are enduring. If designed with local communities, and with clear understanding of goals, risks, and potential outcomes, Portland's GI can achieve more than climate change mitigation, economic development, or avoidance of physical threats. In fact, GI can improve human health, quality of life, environmental quality, and access to nature, while protecting treasured ecosystems and supporting a range of wildlife.

\section{References}

Ahmad M, Arkema C, Berman I, Brownwood B, Chan G, Zhu E (2018). Green infrastructure distribution in Portland, Oregon. Reed College Environmental Studies Junior Seminar. Retrieved from https://www.reed.edu/es/assets/ES300-2018-project-Green-InfrastructureDistribution-FINAL.pdf

Anguelovski I, Connolly JJT, Pearsall H, Shokry G, Checker M, Maantay J et al (2019) Opinion: why green "climate gentrification" threatens poor and vulnerable populations. Proc Natl Acad Sci 116(52):26139-26143. https://doi.org/10.1073/pnas.1920490117

BenDor TK, Shandas V, Miles B, Belt K, Olander L (2018) Ecosystem services and U.S. stormwater planning: an approach for improving urban stormwater decisions. Environ Sci Pol 88:92-103. https://doi.org/10.1016/j.envsci.2018.06.006

Bowen KJ, Lynch Y (2017) The public health benefits of green infrastructure: the potential of economic framing for enhanced decision-making. Curr Opin Environ Sustain 25:90-95. https:/ /doi.org/10.1016/j.cosust.2017.08.003

Caughman L, Plemmons N, Beaudoin F, Crim M, Shandas V (2020) The scenario Collaboratory: a framework for integrating environmental assessments and scenarios into municipal planning. In: Ninan K (ed) Environmental assessments. Edward Elgar Publishing, pp 215-230. https:// doi.org/10.4337/9781788976879.00023 
Chan AY, Hopkins KG (2017) Associations between Sociodemographics and green infrastructure placement in Portland, Oregon. J Sustain Water Built Environ 3(3):05017002. https://doi.org/ 10.1061/JSWBAY.0000827

City of Portland (2010) Portland's green infrastructure: quantifying the health, energy, and community livability benefits. City of Portland bureau of environmental services. Retrieved from https://www.portlandoregon.gov/bes/article/298042

City of Portland (2018) Growing a more equitable urban forest: Portland's Citywide tree planting strategy. Retrieved from: https://www.portland.gov/sites/default/files/2020-09/treeplanting-strategy-12.18.pdf

City of Portland (2021). The Central City 2035 Plan. Retrieved from: https://www.portland.gov/ bps/cc2035/cc2035-documents

Copeland C (2016) Green infrastructure and issues in managing urban stormwater. Congressional Research Service Report 7:5700. Retrieved from https://fas.org/sgp/crs/misc/R43131.pdf

Donovan GH, Butry DT (2011) The effect of urban trees on the rental price of single-family homes in Portland. Oregon Urban Forestry \& Urban Greening 10:163-168

Donovan GH, Michael YL, Butry DT, Sullivan AD, Chase JM (2011) Urban trees and the risk of poor birth outcomes. Health Place 17(1):390-393. https://doi.org/10.1016/ j.healthplace.2010.11.004

Eaton TT (2018) Approach and case-study of green infrastructure screening analysis for urban stormwater control. J Environ Manag 209:495-504. https://doi.org/10.1016/ j.jenvman.2017.12.068

Fahy B, Brenneman E, Chang H, Shandas V (2019) Spatial analysis of urban flooding and extreme heat hazard potential in Portland, OR. Int J Disast Risk Reduc 39:101117. https://doi.org/ 10.1016/j.ijdrr.2019.101117

Foster J, Lowe A, Winkelman S (2011) The value of green infrastructure for urban climate adaptation. The Center for Clean air Policy. Retrieved from http://www.ggi.dcp.ufl.edu/_library/reference/The\%20value\% 20of\%20green $\% 20$ infrastructure $\% 20$ for $\% 20$ urban $\% 20$ climate $\% 20$ adaptation.pdf

Hoffman JS, Shandas V, Pendleton N (2020) The effects of historical housing policies on resident exposure to intra-urban heat: a study of 108 US urban areas. Climate 8(1):12. https://doi.org/ $10.3390 / \mathrm{cli} 8010012$

Jennings V, Johnson Gaither C, Gragg RS (2012) Promoting environmental justice through urban green space access: a synopsis. Environmental Justice 5(1):1-7. https://doi.org/10.1089/ env.2011.0007

Kousky C, Netsil NR, Moldovan-Trujillo G (2020) The mispricing of flood insurance: a look at Portland, Oregon. University of Pennsylvania, Wharton Issue Brief. Retrieved from https://riskcenter.wharton.upenn.edu/wp-content/uploads/2021/01/The-Mispricing-of-FloodInsurance-A-Look-at-Portland-Oregon.pdf

Makido Y, Hellman D, Shandas V (2019) Nature-based designs to mitigate urban heat: the efficacy of green infrastructure treatments in Portland, Oregon. Atmos 10(5):282. https:// doi.org/10.3390/atmos 10050282

Meerow S (2019) A green infrastructure spatial planning model for evaluating ecosystem service tradeoffs and synergies across three coastal megacities. Environ Res Lett 14(12):125011. https:/ /doi.org/10.1088/1748-9326/ab502c

Nascimento LAC, Shandas V (2021) Integrating diverse perspectives for managing neighborhood trees and urban ecosystem Services in Portland, OR (US). Land 10(1):48. https://doi.org/ 10.3390/land 10010048

Naumann S, Davis M, Kaphengst T, Pieterse M, Rayment M (2011) Design, implementation and cost elements of green infrastructure projects. Final report to the European Commission, DG Environment, contract no. 070307/2010/577182/ETU/F.1, ecologic institute and GHK consulting. Retrieved from https://www.ecologic.eu/sites/files/project/2014/documents/designimplementation-cost-elements-of-green-infrastructure-projects-2011-naumann_0.pdf

Netusil NR, Levin Z, Shandas V, Hart T (2014) Valuing green infrastructure in Portland, Oregon. Landsc Urban Plan 124:14-21. https://doi.org/10.1016/j.landurbplan.2014.01.002 
Nowak DJ, Crane DE, Stevens JC (2006) Air pollution removal by urban trees and shrubs in the United States. Urban For Urban Green 4(3-4):115-123. https://doi.org/10.1016/ j.ufug.2006.01.007

Rao M, George LA, Rosenstiel TN, Shandas V, Dinno A (2014) Assessing the relationship among urban trees, nitrogen dioxide, and respiratory health. Environ Pollut 194:96-104. https:/ /doi.org/10.1016/j.envpol.2014.07.011

Shandas V (2015) Neighborhood change and the role of environmental stewardship: a case study of green stormwater infrastructure in the City of Portland (OR, USA). Ecol Soc 20(3):16. https:// doi.org/10.5751/ES-07736-200316

Shandas V, Messer WB (2008) Fostering green communities through civic engagement: community-based environmental stewardship in the Portland area. J Am Plan Assoc 74(4):408418. https://doi.org/10.1080/01944360802291265

Voelkel J, Hellman D, Sakuma R, Shandas V (2018) Assessing vulnerability to urban heat: a study of disproportionate heat exposure and access to refuge by socio-demographic status in Portland, Oregon. Int J Environ Res Public Health 15(4):640. https://doi.org/10.3390/ijerph15040640

Webber JL, Fletcher TD, Cunningham L, Fu G, Butler D, Burns MJ (2020) Is green infrastructure a viable strategy for managing urban surface water flooding? Urban Water J 17(7):598-608. https://doi.org/10.1080/1573062X.2019.1700286

Zhu Z, Ren J, Liu X (2019) Green infrastructure provision for environmental justice: application of the equity index in Guangzhou, China. Urban For Urban Green 46:126443. https://doi.org/ 10.1016/j.ufug.2019.126443

Zölch T, Maderspacher J, Wamsler C, Pauleit S (2016) Using green infrastructure for urban climate-proofing: an evaluation of heat mitigation measures at the micro-scale. Urban For Urban Green 20:305-316. https://doi.org/10.1016/j.ufug.2016.09.011

Open Access This chapter is licensed under the terms of the Creative Commons Attribution 4.0 International License (http://creativecommons.org/licenses/by/4.0/), which permits use, sharing, adaptation, distribution and reproduction in any medium or format, as long as you give appropriate credit to the original author(s) and the source, provide a link to the Creative Commons license and indicate if changes were made.

The images or other third party material in this chapter are included in the chapter's Creative Commons license, unless indicated otherwise in a credit line to the material. If material is not included in the chapter's Creative Commons license and your intended use is not permitted by statutory regulation or exceeds the permitted use, you will need to obtain permission directly from the copyright holder. 